\title{
A Theoretical Study of the Hydride Transfer between 1-Adamantyl Cation and Isopentane
}

\author{
Patrícia D. de Oliveira, ${ }^{a}$ Nilton Rosenbach Jr., ${ }^{a, b}$ Alex P. A. dos Santos ${ }^{a}$ and \\ Claudio J. A. Mota ${ }^{*, a}$ \\ anstituto de Química and INCT de Energia e Ambiente, Universidade Federal do Rio de Janeiro, \\ Cidade Universitária CT Bloco A, 21941-909 Rio de Janeiro-RJ, Brazil \\ ${ }^{b}$ Centro Universitário Estadual da Zona Oeste (UEZO), Colegiado de Produção Industrial, \\ Av. Manuel Caldeira de Alvarenga, 1203, Campo Grande, 23070-200 Rio de Janeiro-RJ, Brazil
}

Foi realizado um estudo teórico da transferência de hidreto entre o cátion 1-adamantila e isopentano, usando a teoria do funcional da densidade em nível PBE1PBE/6-31G(d,p). Os resultados indicaram que há formação de um íon carbônio como intermediário, que é mais estável que os complexos de van der Waals entre os íons carbênios e os alcanos. Os fatores entrópicos são bastante importantes e sobrepujam o termo entálpico à temperatura ambiente.

A density functional teory study of the hydride transfer between 1-adamantyl cation and isopentane has been performed at the PBE1PBE/6-31G(d,p) theoretical level. The results indicate that a carbonium ion is involved as intermediate and is more stable than the van der Waals complexes between the carbenium ions and the alkanes. Entropic factors are important and overcome the enthalpic term at room temperature.

Keywords: hydride transfer, carbocations, adamantane, isopentane

\section{Introduction}

Intermolecular or bimolecular hydride transfer (HT) is a crucial step in acid-catalyzed hydrocarbon transformations. This reaction is involved in the propagation of the catalytic cycle of cracking ${ }^{1,2}$ and alkylation $^{3}$ of hydrocarbons, as well as in the formation of aromatic hydrocarbons ${ }^{4}$ in gasoline and coke,,${ }^{5,6}$ which are carbonaceous materials deposit over the catalyst surface that may lead to loss of activity. Conceptually, HT involves the bimolecular transfer of a hydride from an alkane to a carbenium ion (Scheme 1).

$$
\mathrm{R} \oplus+\mathrm{R}^{\prime}-\mathrm{H} \rightarrow \mathrm{R}-\mathrm{H}+\mathrm{R}^{\prime} \oplus
$$

Scheme 1. Schematic representation of hydride transfer reactions.

In the gas phase, HT is much slower than proton transfer $^{7}$ and shows a negative temperature dependence. ${ }^{8-10}$ The reaction is believed to occur via formation of a "tight"

\footnotetext{
*e-mail: cmota@iq.ufrj.br
}

complex, ${ }^{11,12}$ whose structure may resemble a carbonium ion, ${ }^{13}$ formed by the interaction of the empty p-orbital of a carbenium ion with the $\mathrm{C}-\mathrm{H}$ bond of the alkane. The reaction is used ${ }^{14,15}$ to assess the carbenium ion stability in the gas phase.

In condensed phase, especially on zeolites and other solid acid catalysts, there are few studies regarding hydride transfer. ${ }^{16,17}$ Product distribution obtained from bimolecular alkane reactions is potentially interesting for the evaluation of the HT capability of solid acids. However, the validity of the results depends on the system chosen as model reaction. Indeed, variation of the hydride acceptor seems to affect the rates of hydride transfer to a considerably greater extent, than an equal change of the thermodynamic driving force caused by variation of the hydride donor. ${ }^{18}$ In addition, some systems involve simultaneous reactions competing with HT, and may significantly affect the interpretation of the results.

The 1-adamantyl cation is a stable species ${ }^{19}$ and can be synthesized from the 1-adamantanol and fluorosulfonic acid-antimony pentafluoride. ${ }^{20}$ On the zeolite surface, this species can be also generated from its halide..$^{21}$ In addition 
to the stabilization by $\sigma \mathrm{C}-\mathrm{C}$ bond hyperconjugation, the 1-adamantyl cation has a cage structure, which confers additional stability. Such type of structure allows a better interaction of the unfilled p-orbital inside the cavity with the $\sigma \mathrm{C}-\mathrm{C}$ bonds, known as cage effect. ${ }^{22}$

There are few theoretical studies of the hydride transfer between carbenium ions and alkanes, especially over solid acid catalysts. In gas phase, the reaction proceeds ${ }^{23,24}$ through the formation of carbonium ions as intermediates, which is usually lower in energy than the reactants. In this work, we report a theoretical study of the gas phase HT between the 1-adamantyl cation and isopentane, aiming to calculate the structure and thermodynamic parameters of the intermediates, as a screening model to study the reaction inside the zeolite cages.

\section{Computational methods}

The geometry of the species were fully optimized with the generalized-gradient-approximation exchange-correlation functional of Perdew, Burke, and Ernzerhof (PBE1PBE) and 6-31(d,p) basis set, available in Gaussian 98 package. ${ }^{25}$ Harmonic frequency analysis were performed at the PBE1PBE/6-31G $(\mathrm{d}, \mathrm{p})$ level for all calculated structures to obtain zero-point energies (ZPE) and thermal corrections at $298 \mathrm{~K}$, considering ideal gas approximation. At this theoretical level, basis set superposition error (BSSE) is about $1 \mathrm{kcal} \mathrm{mol}^{-1}$ as shown in previous studies ${ }^{24}$ and they were not considered in the energy calculations. The optimized structures were characterized as minima on the potential energy surface by the absence of imaginary frequencies. Charges at the atomic centers were calculated by fitting to the electrostatic potential derived charges $(\mathrm{CHelpG})$ procedure. ${ }^{26}$

Natural bond orbital (NBO) analysis ${ }^{27}$ was performed at the same level, especially for both van der Waals complexes, to verify electronic interactions that might be relevant to stabilization by hyperconjugation.

\section{Results and Discussion}

Figure 1 shows the calculated structures of the $\mathrm{C}_{15} \mathrm{H}_{27}{ }^{+}$ species. Structures 1a and 1c correspond to the van der Waals complexes between the 1-adamantyl cation and isopentane and the isopentyl cation and adamantane, respectively. In both complexes, the structures of the carbenium ions are similar to the calculated structure for the isolated cation in gas phase. Both carbenium ions are stabilized by hyperconjugation, resulting from electron delocalization of the $\sigma$-bonds to the unfilled p-orbital. Evidences of this type of stabilization in the van der Waals complex 1a can be seen in the shortening of the $\mathrm{C}^{(+)}-\mathrm{C}$ bonds and increasing of the $\mathrm{C}-\mathrm{C} \sigma$-bonds parallel to the unfilled p-orbital. NBO analysis reinforces the hyperconjugation between the $\mathrm{C}-\mathrm{C} \sigma$-bonds and the unfilled p-orbital in the 1-adamantyl cation. In the van der Waals complex 1a, NBO analysis showed that the secondorder perturbation interaction energy $\left(E^{(2)}\right)$ between each $\mathrm{C}-\mathrm{C}$ bond as the donor and the cationic center orbital as the receptor is about $25 \mathrm{kcal} \mathrm{mol}^{-1}$, which is a strong indication of hypercojugation. Moreover, the cationic center has about $18 \%$ of s-orbital character resulting from the orbital interaction with the $\mathrm{C}-\mathrm{C} \sigma$-bonds.

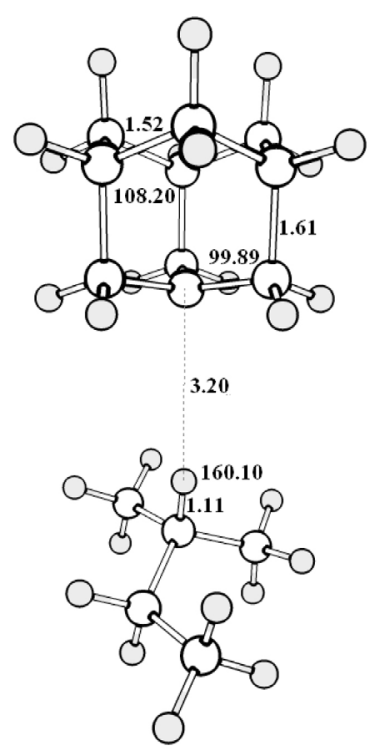

(a)

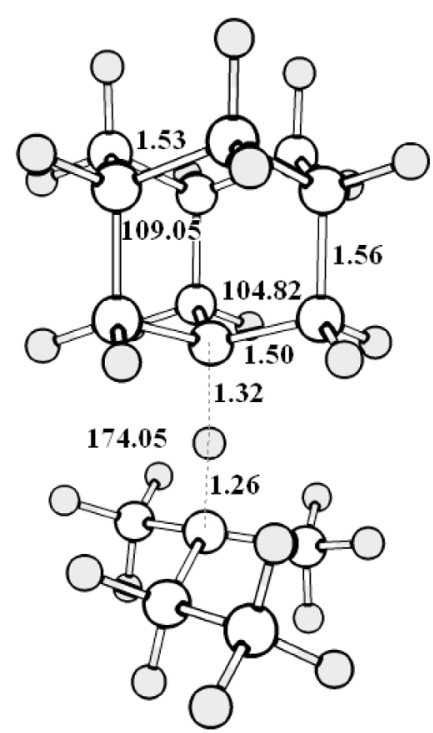

(b)
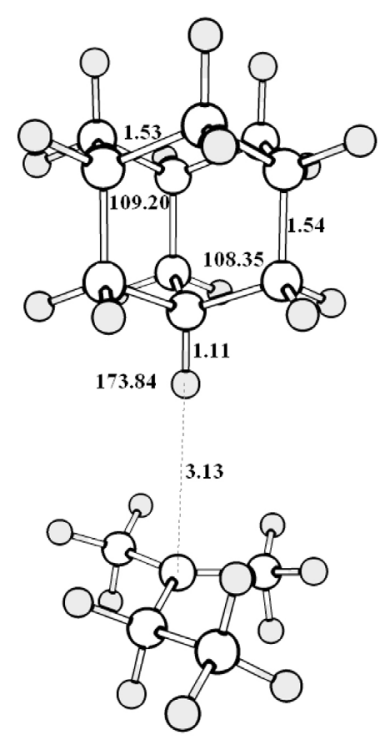

(c)

Figure 1. Structure of the van der Waals complexes $(\mathbf{1 a}, \mathbf{1 c})$ and of the carbonion ion (1b). 
Calculations indicated that carbonium ion $\mathbf{1 b}$ is a minimum on the potential energy surface. This species is characterized by a three center two electron bond (3c-2e), involving two carbon atoms and one hydrogen atom. The structure of the carbonium ion is not symmetrical with respect to the three center bond. The $\mathrm{C}-\mathrm{H}$ bond length with the adamantyl moiety is longer $(1.32 \AA)$ than with the isopentyl moiety (1.26 $\AA$ ), reflecting a more ionic character in the carbon atom of the adamantyl fragment. This can be explained by the higher stabilization of the 1-adamantyl cation with respect to the isopentyl cation, rather than to steric effects. The carbonium ion intermediate also presents a nearly linear structure, with an angle of $174.05^{\circ}$ between the atoms of the three center bond, which is in agreement with experimental data obtained in a crossed beam scattering studies, ${ }^{28}$ as well as with other calculations. ${ }^{24}$

The thermodynamic profile of the hydride transfer involving the 1-adamantyl cation and isopentane is shown in Figure 2. Taking into account the enthalpic term, the formation of the van der Waals complex 1a is exothermic by $2.9 \mathrm{kcal} \mathrm{mol}^{-1}$ with respect to the free reactants. This exothermicity is mostly due to charge dispersion, which was initially concentrated on the 1-adamantyl cation. The formation of the carbonium ion is exothermic by $7.0 \mathrm{kcal} \mathrm{mol}^{-1}$ relative to the reagents. According to vibrational analysis, this species is a minimum on the potential energy surface (no imaginary frequency) and more stable than both van der Waals complexes. The higher stability of the carbonium ion can be ascribed to a better charge dispersion among the atoms and groups of the three center bond.

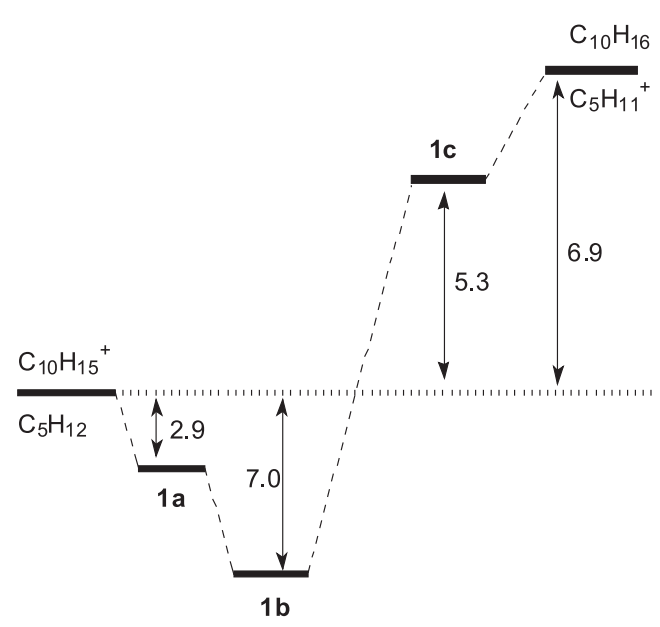

Figure 2. Thermodynamic profile of the reaction between the 1-adamantyl cation and isopentane in the gas phase, calculated at PBE1PBE/6-31G(d,p) level (enthalpy values in $\mathrm{kcal} \mathrm{mol}^{-1}$, figure is not in scale).

The van der Waals complex 1c is $8.2 \mathrm{kcal} \mathrm{mol}^{-1}$ higher in energy than the van der Waals complex 1a. This difference is due to the higher stability of the 1-adamantyl cation compared to the isopentyl cation. Although both cabocations are tertiary and stabilized by hyperconjugation, the additional stability of the 1-adamantyl cation can be attributed to the cage structure of this cation. ${ }^{22}$

We were not able to find the barriers for the formation of the carbonium ion $\mathbf{1 b}$ from either $\mathbf{1 a}$ or $\mathbf{1 c}$ at this level of calculation. In fact, a previous study ${ }^{24}$ of gas phase hydride transfer of a similar system did not characterized the transition states either. This type of reaction may involve extremely low activation barriers, as demonstrated in previous work of the group at higher level of calculations. ${ }^{30,31}$

The hydride transfer from isopentane to 1-adamantyl cation is endothermic by $6.9 \mathrm{kcal} \mathrm{mol}^{-1}$. Alternatively, if we consider the opposite reaction $\left(\Delta \mathrm{H}^{\circ}=-6.9 \mathrm{kcal} \mathrm{mol}^{-1}\right)$, the calculations are in good agreement with previous gasphase equilibrium measurements from mass spectrometry, which indicated an exothercimicity of $7.6 \mathrm{kcal} \mathrm{mol}^{-1}$ for the HT between tert-butyl cation and adamantane, a similar system. $^{29}$

The ChelpG on the carbon and hydrogen atoms involved in the HT process are summarized in the Table 1. In both van der Waals complexes, the charge on the trivalent carbon atoms is comparatively larger, reflecting the carbenium ion character. It is interesting to note that the charge in the cationic carbon of the 1-adamantyl cation is slightly lower than the charge in the cationic carbon of the isopentyl cation, which may partly explain the stability between the two species. The charge distribution in the carbonium ion 1b shows that the carbon atom of the adamantyl moiety bears a more cationic character than the isopentyl carbon atom, in agreement with the geometry calculations.

Table 1. Calculated ChelpG charges in the carbon and hydrogen atoms involved in the hydride transfer, calculated at PBE1PBE/6-31G(d,p) level (the charge refers to the underlined atom)

\begin{tabular}{lccc}
\hline Species & $\begin{array}{c}\text { (adamantyl) } \\
\text { C-H-C } \\
\text { (isopentane) }\end{array}$ & $\begin{array}{c}\text { (admantyl) } \\
\text { C- } \underline{-}-\mathrm{C} \\
\text { (isopentyl) }\end{array}$ & $\begin{array}{c}\text { (adamantane) } \\
\text { C-H- }-\underline{C} \\
\text { (isopentyl) }\end{array}$ \\
\hline vdW complex 1a & +0.601 & -0.160 & +0.393 \\
carbonium ion 1b & +0.678 & -0.179 & +0.394 \\
vdW complex 1c & +0.485 & -0.126 & +0.615 \\
\hline
\end{tabular}

As the degree of freedom decreases from reagents to products, entropic factors might play an important role in the HT reaction, and may overcome the enthalpic term. In fact, if we take into account the entropic contribution, the formation of both van der Waals complexes and the carbonium ion are unfavorable processes. The thermodynamic data for the HT reaction between the 1-adamantyl cation and isopentane at $298 \mathrm{~K}$, in gas phase, are summarized in the Table 2. According to the calculations, the Gibbs free energy difference for the formation of the carbonium ion from 1-adamantyl cation 
and isopentane at $298 \mathrm{~K}$ is endothermic by $5.3 \mathrm{kcal} \mathrm{mol}^{-1}$. This result supports the experimental findings of negative temperature dependence of the hydride transfer in gas phase. ${ }^{8-10}$ As the temperature increases the entropic factor becomes predominant and the reaction becomes unfavorable.

Table 2. Thermodynamic data for the hydride transfer between the 1-adamantyl cation and isopentane at $298 \mathrm{~K}$ in the gas phase, calculated at PBE1PBE/6-31G(d,p) level

\begin{tabular}{lccc}
\hline Species & $\begin{array}{c}\Delta \mathrm{H}^{\circ} \\
\left(\mathrm{kcal} \mathrm{mol}^{-1}\right)\end{array}$ & $\begin{array}{c}\Delta \mathrm{S}^{\circ} \\
\left(\mathrm{cal} \mathrm{mol}^{-1} \mathrm{~K}^{-1}\right)\end{array}$ & $\begin{array}{c}\Delta \mathrm{G}^{\circ} \\
\left(\mathrm{kcal} \mathrm{mol}^{-1}\right)\end{array}$ \\
\hline vdW complex 1a & -2.9 & -46.4 & +10.9 \\
carbonium ion 1b & -7.0 & -41.4 & +5.3 \\
vdW complex 1c & +5.3 & -44.4 & +18.5 \\
\hline
\end{tabular}

\section{Conclusions}

Calculations of the thermodynamic pathway for hydride transfer between the 1-adamantyl cation and isopentane were performed at PBE1PBE/6-31G(d,p) level of theory. The reaction is endothermic by $6.9 \mathrm{kcal} \mathrm{mol}^{-1}$ and involves a carbonium ion as intermediate. The entropic term plays a major role in hydride transfer and may account for the negative temperature dependence of this reaction in gas phase. The structure of the carbonium ion is almost linear with respect to the three center bond, in agreement with kinetic isotope effect for the reaction in solution.

\section{Acknowledgments}

Authors thank CNPq, PRH-ANP and FAPERJ for financial support. Authors also acknowledge the Núcleo de Computação de Alto Desempenho (NACAD) of COPPE/ UFRJ and Centro Nacional de Processamento de Alto Desempenho (CENAPAD) for the use of computational facilities.

\section{References}

1. Corma, A.; Miguel, P. J.; Orchilles, A. V.; J. Catal. 1994, 145, 171.

2. Zhao, Y. X.; Bamwenda, G. R.; Groten, W. A.; Wojciechowski, B. W.; J. Catal. 1993, 140, 243.

3. Weitkamp, J.; Traa, Y.; Catal. Today 1999, 49, 193.

4. Mota, C. J. A.; Rawet, R.; Ind. Eng. Chem. Res. 1995, 34, 4326.

5. Bhatia, S.; Beltramini, J.; Do, D. D.; Catal. Rev. - Sci. Eng. 1989, $31,431$.

6. Bibby, D. M.; Howe, R. F.; McLellan, G. D.; Appl. Catal., A 1992, 93, 1.

7. Meot-Ner, M.; Field, F. H.; J. Am. Chem. Soc. 1975, 97, 2014.
8. Solomon, J. J.; Meot-Ner, M.; Field, F. H.; J. Am. Chem. Soc. 1974, 96, 3727.

9. Hiraoka, K.; Kebarle, P.; J. Chem. Phys. 1975, 63, 394.

10. Meot-Ner, M.; Field, F. H.; J. Am. Chem. Soc. 1978, 100, 1356.

11. Meot-Ner, M.; Field, F. H.; J. Chem. Phys. 1976, 64, 277.

12. Sunner, J. A.; Hirao, K.; Kebarle, P.; J. Am. Chem. Soc. 1989, 93, 4010.

13. Mota, C. J. A.; Quim. Nova 2000, 23, 338.

14. Solomon, J. J.; Field, F. H.; J. Am. Chem. Soc. 1975, 97, 2625.

15. Solomon, J. J.; Field, F. H.; J. Am. Chem. Soc. 1976, 98, 1567.

16. Lukyanov, D. B.; J. Catal. 1994, 145, 54.

17. Platon, A.; Thomson, W. J.; Catal. Lett. 2005, 101, 15.

18. Wurthwein, E. U.; Lang, G.; Schappele, L. H.; Mayr, H.; J. Am. Chem. Soc. 2002, 124, 4084.

19. Esteves, P. M.; Ramirez-Solís, A.; Mota, C. J. A.; J. Phys. Chem. A 2001, 105, 4308.

20. Schleyer, P. V.; Watts, W. E.; Olah, G. A.; Fort, R. C.; Comisaro, M. B.; J. Am. Chem. Soc. 1964, 86, 4195.

21. Franco, M.; Rosenbach, N.; Ferreira, G. B.; Guerra, A. C. O.; Kover, W. B.; Turci, C. C.; Mota, C. J. A.; J. Am. Chem. Soc. 2008, 130, 1592.

22. Olah, G. A.; Angew. Chem., Int. Ed. 1973, 12, 173.

23. Frash, M. V.; Solkan, V. N.; Kazansky, V. B.; J. Chem. Soc., Faraday Trans. 1997, 93, 515.

24. Boronat, M.; Viruela, P.; Corma, A.; J. Phys. Chem. B 1997, 101, 10069.

25. Frisch, M. J.; Trucks, G. W.; Schlegel, H. B.; Gill, P. M. W.; Johnson, B. G.; Robb, M. A.; Cheeseman, J. R.; Keith, T. G.; Peterson, G. A.; Montgomery, J. A.; Raghavachari, K.; AlLaham, M. A.; Zakrzewski, V. G.; Ortiz, J. V.; Foresman, J. B.; Cioslowski, J.; Stefanov, B. B.; Nanayakkara, A.; Challacombe, M.; Peng, C. Y.; Ayala, P. Y.; Chen, W.; Wong, N. W.; Andress, J. L.; Replogle, E. S.; Gomperts, R.; Martin, R. L.; Fox, D. L.; Binkley, J. S.; Defrees, D. J.; Baker, J.; Stewart, J. P.; HeadGordon, M.; Gonzalez, C.; Pople, J. A.; Gaussian 98. Gaussian Inc.: Pittsburg, PA, 1998.

26. Breneman, C. M.; Wiberg, K. B.; J. Comput. Chem. 1990, 11, 361.

27 Reed, A. D.; Weinhold, F.; Isr. J. Chem. 1991, 31, 277.

28. Zabka, J.; Farnik, M.; Dolejsek, Z.; Polach, J.; Herman, Z.; J. Phys. Chem. 1995, 99, 15595.

29. Sharma, R. B.; Sensharma, D. K.; Hiraoka, K.; Kebarle, P.; J. Am. Chem. Soc. 1985, 107, 3747.

30. Esteves, P. M.; Mota, C. J. A.; Solís, A. R.; Lamoneda R. H.; J. Am. Chem. Soc. 1998, 120, 3213.

31. Esteves, P. M.; Alberto, G. G. P.; Solís, A. R.; Mota, C. J. A.; J. Phys. Chem. A 2000, 104, 6233.

Submitted: February 11, 2010 Published online: September 2, 2010 